\title{
“UM CONTO DE DUAS CIDADES”: O TRICENTENÁRIO DE CAMÕES EM LISBOA E
} NO RIO DE JANEIRO

\section{"UN CUENTO DE DOS CIUDADES": EL TRICENTENARIO DE CAMÕES EN LISBOA Y EN RÍO DE JANEIRO}

\section{"A TALE OF TWO CITIES": THE TRICENTENARY OF CAMÕES IN LISBON AND IN RIO DE JANEIRO}

\section{“LE CONTE DE DEUX CITÉS»: LE TRICENTENAIRE DE CAMÕES À LISBONNE ET RIO DE JANEIRO}

DOI: 10.5533/1984-2503-20124102

Giselle Martins Venâncio ${ }^{1}$

\section{RESUMO}

Este texto trata das comemorações do tricentenário de morte de Luis de Camões em Lisboa e no Rio de Janeiro, em 1880. Investiga-se este evento como paradigmático das maneiras elaboradas por intelectuais de ambos os países no sentido da valorização dos aspectos culturais luso-brasileiros, em fins do século XIX. Considera-se, neste texto, a relação cultural e política em curso entre Portugal e Brasil, naquele período, destacandose 0 fato de que as comemorações do tricentenário enfatizaram, na ação de seus organizadores, um ideal de identidade nacional brasileira definida como fundamentalmente lusitana.

Palavras-chave: luso-brasileirismo, Camões, comemoração.

\section{RESUMEN}

Este artículo aborda las celebraciones del tricentenario de la muerte de Luis de Camões en Lisboa y Río de Janeiro en 1880. Se examina el caso como paradigma de las formas elaboradas por intelectuales de ambos países en la recuperación de los aspectos culturales luso-brasileños a fines del siglo XIX. Se considera en este texto, las relaciones culturales y políticas en marcha entre Portugal y Brasil, en ese período, destacando el hecho de que las celebraciones del tricentenario enfatizaron, en la acción de sus

\footnotetext{
${ }^{1}$ Professora Adjunta do Departamento de História e do Programa de Pós-Graduação em História da Universidade Federal Fluminense (UFF). E-mail: gmvenancio@yahoo.com
} 
organizadores, un ideal de identidad nacional brasileña definida como fundamentalmente lusitana.

Palabras-clave: luso-brasileirismo, Camões, celebración.

\section{ABSTRACT}

This text discusses the tercentenary celebrations of the death of Luis de Camões in Lisbon and in Rio de Janeiro in 1880. The event is investigated as paradigmatic of the methods used by intellectuals in both countries to valorise features of Luso-Brazilian culture at the end of the $19^{\text {th }}$ century. The text considers the cultural and political relations between Portugal and Brazil in the period, highlighting the fact that the tercentenary celebrations emphasized, through the organizers' activities, an ideal national Brazilian identity defined as fundamentally 'Luso'.

Key words: Luso-Brazilianism, Camões, commemoration.

\section{RÉSUMÉ}

Ce texte aborde les commémorations du tricentenaire de la mort de Luis de Camões à Lisbonne et Rio de Janeiro en 1880. L'événement sera étudié en tant que symbole de la manière dont les intellectuels des deux pays mettaient en œuvre la valorisation d'aspects culturels luso-brésilien à la fin du XIX ${ }^{\text {ème }}$ siècle. L'on prendra ici en considération la relation culturelle et politique en vigueur à l'époque entre le Brésil et le Portugal, en soulignant le fait que les commémorations du tricentenaire ont représenté dans l'esprit de leurs organisateurs un idéal d'identité nationale brésilienne définie comme fondamentalement lusitaine.

Mots-clés : identité luso-brésilienne, Camões, commémoration.

Estiveram animadissimos os festejos de ant-hontem n'esta capital, em homenagem ao terceiro centenario do sublime poeta.

Desde pela manhã o movimento nas ruas era immenso, e via-se claramente que toda a população alliava-se á festa que se celebrava em honra do grande cantor dos Lusiadas, cujo nome era repetido de bocca em bocca por todos os que brazileiros e portuguezes - fallam a lingua do immortal poeta.

As principaes ruas da cidade, quasi todas cobertas de folhas, apresentavam um aspecto de animada festa; das janellas dos sobrados pendiam grande numero de bandeiras de todas as nacionalidades, destacando-se entre essas a portugueza e a brazileira; em mais de um logar exhibiu-se o retrato ou o busto do poeta cujo centenario se commemorava.

Em quasi todas as repartições publicas houve feriado, e foram encerrados os 
trabalhos em todos os estabelecimentos particulares, notando-se que a essa manifestação a que ajuntava-se o movimento espontâneo do povo, veiu tambem alliar-se o commercio, cujas portas fecharam desde cedo ${ }^{2}$.

A Gazeta de Notícias do dia 11 de junho de 1880 anunciava e narrava, com riqueza de detalhes, as festas em comemoração ao tricentenário de morte do poeta português Luis de Camões, realizadas no Rio de Janeiro. Como se pode ler nas páginas do periódico, o evento mobilizou, de forma intensa, o espaço cultural e intelectual da cidade nos primeiros dias de junho de 1880. Houve festa nos teatros, concertos, regatas, exposição na Biblioteca Nacional, uma profusão de eventos que marcava a adesão da cidade brasileira às comemorações realizadas em Portugal com os mesmos objetivos.

Pelo que se lê, é possível afirmar que a festa em torno do nome de Camões atingiu amplos espectros da sociedade brasileira, conseguindo congregar diferentes segmentos. Além disso, o tricentenário foi comemorado como um indício certeiro da importância da cultura portuguesa para o país ${ }^{3}$.

Contudo, se em Portugal esta festa é já amplamente conhecida, e registrada pela historiografia, no Brasil há um profundo desconhecimento a respeito desta comemoração. Isso se dá, especialmente, pelo fato de que, em larga medida, a historiografia brasileira registra um distanciamento entre Portugal e Brasil na segunda metade do século XIX. Os poucos trabalhos que se referem às formas de aproximação entre estes dois países, limitam-se a investigar os aspectos diplomáticos dessa relação, negligenciando, largamente, as relações culturais, intelectuais e editoriais.

Ao analisar particularmente as políticas diplomáticas oficiais, os estudos constroem uma temporalidade que considera que apenas nos primeiros anos do século $X X$ ou, mais precisamente, a partir das comemorações do centenário da independência em 1922, essa aproximação se deu, como pode se ler na análise desenvolvida por Tânia Bessone e Lucia Neves, quando afirmam:

De fato, foi sobretudo após 1922 que começou a ser gerada a política de relações fraternais entre Brasil e Portugal que passaria a permear as relações oficiais lusobrasileiras daí em diante, fundada no sentimento de pertencimento a uma tradição histórica e cultural comum visando a minimização dos conflitos e das divergências. A partir e então e apesar da reafirmação nacionalista que representou, nesse mesmo momento,o movimento modernista, Brasil e Portugal voltavam a se ver como pátrias irmãs, unidas pela língua, pelas tradições e representações comuns

\footnotetext{
${ }^{2}$ Gazeta de Notícias, 11 e 12 de junho de 1880, p. 1

3 Venâncio, Giselle Martins (2010). "Comemorar Camões e repensar a nação: o discurso de Joaquim Nabuco na festa do tricentenário de Camões no Rio de Janeiro". (mimeo)
} 


$$
(\ldots)^{4} \text {. }
$$

No entanto, já é possível identificar um conjunto de pesquisas que trabalham com a hipótese que a "independência da colônia, em 1822 (...) não conduz[iu] ao desaparecimento da existência de referentes provenientes do Brasil na cultura portuguesa, nem tão pouco [significou] a ruptura de ligação entre os dois Estados'5 . Pelo contrário, estudos mais recentes, demonstram que parte das relações entre Brasil e Portugal (...)

(...), na primeira metade do século $X X$, foram arquitetadas por uma quantidade significativa de intelectuais, interessados na afirmação do universo cultural brasileiro, como tributário do português ${ }^{6}$.

Investigar, portanto, estas formas de aproximação entre os dois países é tarefa importante para se compreender os processos de organização e consolidação de formas de pensamento elaboradas tanto em Portugal quanto no Brasil. Nesse sentido, a festa do tricentenário de morte de Camões, realizada em 1880, emerge como um evento paradigmático das maneiras elaboradas por intelectuais de ambos os países no sentido da valorização dos aspectos culturais luso-brasileiros, em fins do século XIX.

\section{A festa em Lisboa: referência para a brasileira}

Segundo Maria Isabel João ${ }^{7}$, em Portugal, foi Luciano Cordeiro, secretário perpétuo da Sociedade de Geografia e jornalista d'O Comercio de Lisboa que decidiu convocar uma grande reunião da imprensa da capital para estabelecer os eventos que seriam realizados para comemorar Camões. A partir daí, um grupo de indivíduos ligados a imprensa de Lisboa tomou a frente da promoção da festa. Segundo essa mesma autora, o fato da organização ter sido realizada por uma comissão de imprensa garantiu um movimento de solidariedade e adesão dos jornais de todo o país. A festa espalhou-se por

\footnotetext{
${ }^{4}$ Ferreira, T. e Neves, Lucia. "As relações culturais ao longo do século XIX". In: Cervo, A. e Magalhães, J. C (2000). Depois das caravelas: as relações entre Portugal e Brasil, 1808-2000, Brasília: Editora da Universidade de Brasília, p. 232.

${ }^{5}$ Nunes e Miranda (1999). Op. cit, p. 697.

${ }^{6}$ Serpa, Élio (2001). "Brasil e Portugal nas revistas portuguesas: língua, literatura e história". In: Ramos, Maria Bernadete, Serpa, Élio e Paulo, Heloísa (orgs.) (2001). O beijo através do Atlântico: o lugar do Brasil no panlusitanismo, Chapecó: Argos, p. 89.

${ }^{7}$ João, Maria Isabel (2002). Memória e Império: comemorações em Portugal (1880-1960). Lisboa: Fundação Calouste Gulbenkian.
} 
várias cidades além de Lisboa, como Aveiro, Porto, Coimbra, entre outras. Os jornais e revistas publicaram números especiais ou dedicaram páginas específicas para evocar a memória de Camões. Na fala expressa nos jornais e revistas portuguesas, urgia comemorar Camões visto que essa era uma "festa da nação" e não a "festa de um partido, de uma escola, de uma comunhão parcial'. Também o programa aprovado pela comissão de imprensa previa que o centenário "tinha o objetivo de estabelecer a convergência de todos os indivíduos em torno da Pátria de que Camões seria o símbolo",

A elevação de Camões ao panteão dos heróis nacionais era, portanto, um dos mais claros e presentes objetivos da festa. Considerando-se que "o trabalho de heroificação é inseparável da produção de uma memória coletiva"10 um conjunto de publicações que evocava a memória de Camões e fortalecia o estabelecimento de uma íntima relação entre os poemas camonianos e a glorificação da história pátria, unificando a figura do poeta a de grande patriota, pois que autor de páginas gloriosas da biografia da Nação portuguesa.

A festa em Portugal realizou-se, portanto, com a publicação de inúmeros impressos, a criação de pinturas, moedas comemorativas, festas nas escolas, procissões cívicas, discursos pronunciados e publicados, uma ampla variedade de eventos que atendia a indivíduos dos mais variados espectros políticos. A vastidão da festa foi tal que levou Oliveira Martins a afirmar, em 1880: "Camões é ao mesmo tempo uma infinidade de tipos para uma infinidade de criaturas arrastadas pelo Centenário"11. Monarquistas e republicanos articularam o culto ao poeta aos seus ideais político-ideológicos.

Do ponto de vista dos monarquistas Camões havia dado expressão aos três elementos que caracterizavam a nacionalidade: a tradição, a língua e o território, aspectos que foram valorizados pela sua escrita. Já sob o olhar dos republicanos, evocar o poeta era lembrar o passado como forma de superar as dificuldades de um presente de "apagada e vil tristeza" - nas próprias palavras de Camões, bastante repetidas -, e de estimular os ânimos para as mudanças políticas ${ }^{12}$. Na fala de um dos organizadores, citada por Isabel João, "relembrar os mortos [era] estimular os vivos; recordar Os Lusíadas [era] reviver a melhor época da nacionalidade portuguesa, e acordar um mundo

\footnotetext{
${ }^{8}$ Ibidem.

${ }^{9}$ lbidem.

${ }^{10}$ Ribeiro, Fernando Bessa (2005). "A invenção dos heróis: Nação, história e discursos de identidade em Moçambique”. Etnográfica, vol. IX, n. 2, p. 258. Acessado em 30/09/2010.

${ }^{11}$ Martins, Oliveira (1986). Camões, Os Lusíadas e a Renascença em Portugal, Lisboa, 1986. Apud João, M. I. (2002). Op. cit, p. 525.

12 Ibidem.
} 
onde Portugal foi senhor, foi grande, foi onipotente"13. Assim, o Camões e Os Lusíadas dos republicanos portugueses eram, antes de tudo, uma bandeira de luta contra a decadência nacional e a justificativa para a retomada dos valores mais genuinamente portugueses ligados ao heroísmo, a expansão, ao crescimento e ao desenvolvimento da Nação.

Mas, se a festa portuguesa é bastante conhecida, o mesmo não acontece com a comemoração que ocorreu no Rio de Janeiro.

A glorificação de Camões por amplos grupos intelectuais portugueses repercutiu de forma intensa no Brasil, especialmente no Rio de Janeiro. Há quem afirme que mais que uma aproximação entre portugueses e brasileiros, a festa do tricentenário de Camões foi a data que permitiu a formalização de "relações estreitas entre os movimentos republicanos brasileiro e português"14.

Embora não seja ainda possível demonstrar se houve mesmo esta aproximação entre os republicanos portugueses e brasileiros, realizada por ocasião do tricentenário, é certo que a festa no Rio de Janeiro colocou em pauta a questão da discussão sobre um ideal de nacionalidade brasileira que deveria se definir em continuidade a sua herança portuguesa.

Ainda que, nesse momento, os intelectuais brasileiros estivessem mais preocupados com a constituição de um ideal de nacionalidade que se plasmava, em grande medida, por um discurso de oposição à produção intelectual da antiga metrópole, as falas e eventos da festa do tricentenário de Camões elaboraram-se num campo condicionado por um mito de fundação da identidade nacional brasileira que era, na opinião de seus mentores, na origem e fundamentalmente, lusitano. Assim, o que se constituiu como brasilidade, nesse momento, foi num certo sentido também lusitanidade ${ }^{15}$, pois Camões deixou de ser visto apenas como o "representative man da alma portuguesa"16 , para tornar-se um "patrono recuado também da nacionalidade brasileira"17.

A festa em torno do nome de Camões no Rio de Janeiro conseguiu, assim como em Portugal, congregar diferentes segmentos sociais que a vivenciaram como um indício certeiro da importância da cultura portuguesa para o Brasil.

\footnotetext{
13 Ibidem.

14 Barbosa, Luisa Maria. O Brasil e o movimento republicano português, 1880-1910 (mimeo).

15 Serrano, Gisella Amorim (2009). Caravelas de papel. Tese (Doutorado) - UFMG, Belo Horizonte, p. 26.

16 Catroga, Fernando (2005). Nação, mito e rito: religião civil e comemoracionismo, Fortaleza: Edições NUDOC/Museu do Ceará, p. 120.

17 Sandmann, Marcelo (2003). "Marcelo Corrêa. As comemorações do tricentenário de Camões no Brasil". Revista Letras, Curitiba, n. 59, jan./jun., Editora UFPR, p. 202.
} 
Nessa cidade, os membros da colônia portuguesa, particularmente aqueles que se reuniam na diretoria do Gabinete Português de Leitura, tomaram a frente das comemorações, elaborando a noção de um ideário festivo no qual o Brasil aparecia como uma continuação de Portugal na América. O Brasil e os brasileiros eram, desse modo, vistos não numa ótica de alteridade, mas como uma parte da cultura e da sociedade portuguesa. Eram, na verdade, considerados o exemplo máximo da capacidade de Portugal como país colonizador.

\section{A festa no Rio de Janeiro: tributo brasileiro a cultura portuguesa}

Na medida em que se aproximava a semana em torno do dia 10 de junho de 1880 , data marcada para a festa, os grupos interessados em tomar parte na celebração anunciavam seus programas comemorativos ${ }^{18}$.

O programa elaborado pelo Gabinete Português de Leitura, esboçado ainda em 1879, incluía originalmente a distribuição gratuita de exemplares comemorativos d'Os Lusiadas no Brasil e em Portugal, a realização de um festejo artístico e, como momento máximo da festa, a colocação da pedra fundamental do edifício projetado para abrigar a biblioteca do Gabinete. Como afirmou naquela ocasião, Eduardo Lemos, então presidente da instituição:

Ligar o nome de Camões ao nosso instituto por um laço perpetuo, por um vinculo de marmore, foi o primeiro pensamento da directoria. Neste intuito projecta-se com a maior solemnidade a fundação da primeira pedra do novo edificio para a nossa bibliotheca, no dia do memorando centenario $^{19}$.

Quando anunciadas ao público nas páginas do Jornal do Commercio do dia 07 de março de 1880, o plano traçado pela diretoria do Gabinete já constava das manifestações festivas $^{20}$.

Porém, somente no dia 9 de Junho, às vésperas do centenário, seria divulgado

\footnotetext{
${ }^{18}$ Um levantamento realizado no Jornal do Commercio e na Gazeta de Notícias no primeiro semestre de 1880 mostra que houve uma intensa movimentação em torno da festa na cidade do Rio de Janeiro.

${ }^{19}$ Lemos, Eduardo. Discurso proferido pelo presidente da directoria na sessão de posse do conselho deliberativo em 18 de Junho de 1879, p.18.

${ }^{20}$ Jornal do Commercio, 07/03/1880, n. 67, p. 01.
} 
pelo Gabinete Português de Leitura o programa do seu festejo de forma detalhada: a festa começaria às onze horas da manhã com o assentamento da pedra fundamental do novo edifício do Gabinete, haveria discursos, leitura e assinatura do auto de assentamento, entrega de medalhas - sendo a primeira destinada ao Imperador D. Pedro II -, oferta da edição comemorativa d'Os Lusiadas à Biblioteca Nacional e a vinte e nove pessoas e instituições escolhidas pelo Gabinete ${ }^{21}$. Além disso, haveria uma festa à noite, começando às oito horas, no Imperial Theatro D. Pedro II. Esta contaria com um "grande festival litterario e artístico" que teria a presença do Imperador e da Imperatriz, de membros do Ministério, do Senado, da Câmara dos Deputados, do Supremo Tribunal, do Instituto Histórico, do ministro e do cônsul de Portugal, bem como de membros do corpo diplomático e do corpo consular.

$\mathrm{Na}$ primeira etapa do evento, os indivíduos e as corporações que desejassem prestar sua homenagem ao poeta se reuniriam no palco do teatro para depositar coroas, insígnias e bandeiras em torno da efígie de Camões, presente em lugar de destaque ${ }^{22}$. Em seguida, a orquestra tocaria o hino nacional brasileiro e, logo após, Joaquim Nabuco proferiria o discurso inaugural ${ }^{23}$. Ainda seriam recitadas poesias antes do encerramento marcado pelo hino nacional português.

A segunda etapa seria dedicada à apresentação, em um único ato, da peça Tu só, tu, puro amor, escrita por Machado de Assis especialmente para o centenário. Por fim, a apresentação da orquestra e das bandas marciais ocuparia a última parte do festejo. Ainda indicava-se, no programa divulgado, que haveria a distribuição de milhares de exemplares de excertos dos mais notáveis trechos d'Os Lusíadas, como também de outras obras de Camões $^{24}$.

A se crer no que noticiou a Gazeta de Notícias em 12 de junho de 1880, a festa foi um sucesso. A inauguração da pedra fundamental do novo prédio do Gabinete Português de Leitura contou com a presença de inúmeros convidados, autoridades, além do Imperador. O jornal narra o acontecimento com as seguintes palavras:

\footnotetext{
21 Jornal do Commercio, 09/06/1880, n. 160, p. 05.

22 Deste ato, como se verificou posteriormente, participaram centenas de pessoas representando associações científicas e literárias, como a Secção da Sociedade de Geographia de Lisbôa no Brazil, o Lyceu de Artes e Officios, e o Lycêo Litterario Portuguez.

${ }^{23}$ Sobre o discurso de Joaquim Nabuco na festa do tricentenário de Camões, ver: Venancio, Giselle M. Comemorar Camões e repensar a nação: o discurso de Joaquim Nabuco na festa do tricentenário de Camões no Rio de Janeiro. (mimeo)
}

24 Jornal do Commercio, 09/06/1880, n. 160, p. 05. 
Desde ás 10 horas da manhã começou a affluencia do povo para as immediações do local onde devia dar-se a ceremonia e que fora convenientemente preparado e disposto para a festa. Logo depois entraram a chegar os convidados para a solemnidade, e cujos carros, em numero extraordinario, tiveram de occupar todas as ruas e praças adjacentes, ao longo das do Sacramento, Theatro, travessa das Bellas Artes e Leopoldina, largo de S. Francisco de Paula e Constituição. Fizeramse representar na ceremonia todas as corporações scientificas e litterarias d'esta corte, instituições beneficentes, o commercio, a imprensa, o parlamento, a municipalidade, o exercito, a marinha, etc. Entre as commissões de sociedades viam-se: a do Club Gymnastico Portuguez, com a sua banda de musica á frente; a do Lyceu Litterario Portuguez, (...) a da Imperial Sociedade Amante da Instrução, representada por sua diretoria, (...) a da IIIma. camara municipal da corte, representada por seus membros, tendo á frente o seu procurador, que carregava a bandeira da municipalidade; a do Instituto Histórico e Geographico Brazileiro, representada pelo seu presidente visconde do Bom Retiro e outros membros; a do Lyceu de Artes e Officios, representada por seu director e alguns dos professores; a da Faculdade de Medicina da corte; a da Escola Polytechnica; a da Sociedade Portugueza de Beneficencia e secção da Sociedade de Geographia de Lisboa, representadas pelo Sr. Conde de S. Salvador de Mattosinhos e outros socios; a do Retiro Litterario Portuguez, etc. Entre os cavalheiros representantes das mais elevadas classes sociaes, via-se grande numero de senadores, deputados, o Sr. ministro do imperio, o Sr. consul de Portugal acompanhado de sua Exma. Senhora, officiaes superiores do exercito e marinha, o Rev. Cura da freguezia, representantes do Jornal do Commercio, Cruzeiro, Diario Official, Revista Illustrada e da Gazeta de Noticias, representada por seu redactor principal ${ }^{25}$.

Diante de todas as autoridades presentes, o presidente do Gabinete Português leu o auto de assentamento da pedra fundamental - realizado pelo Imperador D. Pedro II que foi assinado pelos presentes:

\begin{abstract}
Aos dez dias do mez de junho de 1880, era memoravel do terceiro centenario do grande poeta Luiz de Camões. 59 da Independencia e do Imperio reinando S. M. o Imperador o Senhor D. Pedro II, n'esta muito leal e heroica cidade de S. Sebastião do Rio de Janeiro, freguezia do Sacramento e rua de Luiz de Camões, achando-se presente o mesmo Augusto Senhor, representadas a IIIma. camara municipal, o alto funccionalismo do Estado, o corpo diplomatico, corporações litterarias e scientíficas e diversas sociedades, a imprensa, o commercio, as industrias, grande numero de convidados, a directoria, o conselho deliberativo e muitos socios e subscriptores d'esta associação instructiva, depois de benzida segundo o ritual romano pelo vigario respectivo, foi por sua Magestade o Imperador assentada a pedra fundamental do edificio qu epara a sua actual bibliotheca e para a de livros elementares e cursos publicos, faz construir a associação denominada Gabinete Portuguez de Leitura no Rio de Janeiro, creada n'esta cidade em 1837. Assim inaugurada com toda a solemnidade a construcção do mencionado edificio, lavrouse este auto, que vai assignado por Sua Magestade e pessoas presentes; e outro de igual theor, escriptos pelo $2^{\circ}$ secretario, e authenticados e selados pelo $1^{\circ}$ secretario d'esta associação ${ }^{26}$.
\end{abstract}

$\mathrm{Na}$ noite daquele mesmo dia, a festa teve continuidade no Theatro D. Pedro, ricamente decorado para o evento e repleto dos mais ilustres personagens da sociedade

\footnotetext{
${ }^{25}$ Gazeta de Notícias, 11-12 de junho de 1880, n. 161, Ano IV, p. 1.

${ }^{26}$ Auto do assentamento da pedra fundamental do edificio para a bibliotheca do Gabinete Portuguez de Leitura no Rio de Janeiro. Gazeta de Notícias, 11-12 de junho de 1880, n. 161, Ano IV, p. 1
} 
do Rio de Janeiro. A Gazeta de Notícias descreve o evento, em suas páginas, destacando seu luxo e beleza:

(...) o grande numero de luzes dava ao theatro um aspecto brilhatissimo.Os camarotes estavam litteralmente guarnecidos de senhoras, que trajavam elegantes e riquissimos vestuarios de gala, fazendo reluzir joias de subido valor. Em geral e principalmente nos camarotes, varandas e cadeiras de primeira classe dos homens estavam de casaca preta.S. M. o Imperador trazia a farda de almirante e S. M. a Imperatriz trajava um rico vestido azul coberto de rendas brancas. Além dos Srs. Ministros do imperio, agricultura, marinha e negocios estrangeiros, muitos altos funccionarios ostentavam as suas fardas. Executado $o$ hymno nacional pela orchestra, subiu o panno para o acto da commemoração. $A$ scena estava preparada com grande luxo. Ao lado direito do espectador estava 0 busto do poeta, sob um rico docel e espaldar de damasco amarello, sendo o exterior, bem como a cupula em fórma de corôa, de velludo carmezim guarnecido de listrões e franjas de ouro. O pedestal bem como os degráus em que elle assentava, estavam cheios de coroas. Dos bastidores sahiam os riquissimos estandartes das diversas corporações que se fizeram representar. Ao fundo, do lado esquerdo, o panno representava a torre de Belém e o Tejo com alguns galeões.(...)No centro da scena estava uma tribuna coberta pelas bandeiras nacional e portugueza. Do lado esquerdo do busto formaram os representantes de diversas sociedades e membros da directoria e conselho do Gabinete Portuguez de Leitura.Do lado direito estavam os representantes das corporações scientificas, artisitcas e da imprensa.Apenas terminou o hymno, occupou a tribuna o Sr. Dr. Joaquim Nabuco que proferiu o discurso que se acha impresso e que provocou os mais enthusiasticos applausos.

Como se pode perceber dos registros encontrados na Gazeta, a festa congregou diversas instituições e autoridades, e pautou-se numa idéia de que aos brasileiros urgia comemorar Camões, pois neste poeta residia toda a origem da alta cultura brasileira necessariamente tributária da portuguesa.

Ainda neste mesmo dia, inaugurou-se, na Biblioteca Nacional, com a presença do Imperador D. Pedro II, a exposição camoneana, organizada por seu diretor Ramiz Galvão. Esta reunia um grande número de obras artísticas relacionadas ao grande poeta lusitano, destacando-se os diversos exemplares d'Os Lusiadas cedidos pelo Gabinete Português de Leitura, além de obras emprestadas por particulares, pelo Retiro Literário Português, pela Sociedade Portuguesa de Beneficência e pelo próprio Imperador.

Conta-se que a exposição despertou considerável interesse do público, de modo que, segundo o Jornal do Commercio, nos dias de 10 a 12 de Junho, a Biblioteca Nacional teria recebido aproximadamente 10.000 visitantes $^{27}$.

É importante considerar que esse número significa uma grande dinamização do público da biblioteca naquele momento, pois a partir do que registram os documentos da

\footnotetext{
${ }^{27}$ Jornal do Commercio, 14/06/1880, n. 164, p. 01.
} 
época, a quantidade de visitantes na Biblioteca Nacional naquele período girava em torno de, no máximo, cerca de 9000 pessoas ao ano, como se pode ver na tabela abaixo:

Número de leitores que frequentaram a biblioteca (1871-1881)

\begin{tabular}{|l|l|}
\hline Ano & Número de leitores \\
\hline 1871 & 2834 \\
\hline 1872 & 8569 \\
\hline 1873 & 7438 \\
\hline 1874 & 6220 \\
\hline 1875 & 4399 \\
\hline 1876 & 4415 \\
\hline 1877 & 7064 \\
\hline 1878 & Não consta relatório \\
\hline 1879 & 8485 \\
\hline 1880 & 9625 \\
\hline 1881 & 9180 \\
\hline
\end{tabular}

Fonte: Relatórios do Ministério do Império ${ }^{28}$

Estes dados evidenciam ainda mais a importância do público da exposição camoneana estimada, no relatório elaborado por Ramiz Galvão, diretor da biblioteca, em doze mil visitantes, em seis dias. Este relevante afluxo de pessoas contribuiu, sem dúvida, para a decisão de prorrogação da exposição até o dia 15 do mesmo mês, por concessão do Ministro do Império ${ }^{29}$.

Os teatros também não ficaram alheios ao Tricentenário. No dia nove de Junho, o Theatro Phenix Dramatica organizou um espetáculo para celebrar o especial momento, enquanto que, no mesmo dia, fora realizada uma "Grande Festa Artistica" no Theatro S. Luiz. No dia treze, também no Theatro $S$. Luiz, foi apresentado um espetáculo com o "Hymno a Camões" e a peça "Luiz de Camões", enquanto que o Theatro Recreio Dramatico realizou um espetáculo com "Camões e a História" e "Hymno a Camões".

Algumas organizações prestaram honras a Camões de maneira mais discreta,

\footnotetext{
${ }^{28}$ Apud Caldeira, Ana Paula Sampaio (2009). A biblioteca Nacional nos tempos de Ramiz Galvão (18701882), Rio de Janeiro: Biblioteca Nacional, p. 57.

${ }^{29}$ Jornal do Commercio, 14/06/1880, n. 164, p. 01.
} 
como a Imperial Sociedade União Beneficente Vinte e Nove de Julho e a Sociedade União Beneficente Commercio e Artes, que fecharam suas secretarias em vista da comemoração. As lojas maçônicas Grande Oriente Unido do Brazil e Grande Oriente Brazil declararam a suspensão de seus trabalhos com o mesmo intuito. A diretoria da Sociedade União Commercial dos Varegistas de Secos e Molhados fez convite a seus sócios para que, no dia 10 de Junho, iluminassem e embandeirassem seus estabelecimentos, "fechando-os total ou parcialmente ás 3 horas da tarde, conforme Ih'o dictarem os seus interesses e conveniencias dos seus freguezes". E estendia ainda o pedido aos comerciantes que atuassem no ramo e que não faziam parte desta sociedade, "acompanhado-a assim na homenagem ao genio mais transcendente das letras patrias."

Além de todas essas comemorações, talvez a mais significativa tenha sido a regata realizada na Enseada de Botafogo. Marcada por seu aspecto grandioso, a regata pretendia vir a ser a maior celebração do Rio de Janeiro. No dia 20 de maio de 1880, 0 Club de Regatas Guanabarense anunciou pelos jornais a intenção de realizar uma regata no dia 13 do mês seguinte. A convocação para os interessados, fez-se então publicar no dia 24 do mesmo mês. No programa, divulgado uma semana após o primeiro informativo, indicava-se que a regata teria início às três horas da tarde e contaria com galeões ornamentados que juntos formariam um corredor por onde navegariam as vinte sete embarcações concorrentes - tripuladas por equipes de militares, profissionais e amadores - todas elegantemente ornadas e nomeadas em lembrança aos "feitos cantados pelo grande épico,30. Os prêmios disputados seriam doze exemplares d'Os Lusiadas e duas medalhas de bronze doadas pelo Gabinete Português de Leitura e que na ocasião da premiação seriam entregues pelo Imperador D. Pedro II.

Para o "festejo em terra" seria construído um pavilhão dedicado à família imperial e uma arquibancada capaz de abrigar os representantes dos poderes públicos, as comissões e os demais convidados. A praia de Botafogo estaria ornamentada e embandeirada, e esperava-se que os moradores da orla também enfeitassem e iluminassem suas casas e jardins. Estaria presente a maioria das sociedades musicais da "côrte e de Nitherohy" que, tomando seus lugares na praia de Botafogo, executariam seus repertórios durante a celebração.

A comissão organizadora também planejava que diversas embarcações percorressem a praia no decorrer do "festejo marítimo", entre elas vinte "gôndolas

${ }^{30}$ Jornal do Commercio, 27/05/1880, n. 147, p.02. 
venezianas" que conduziriam conjuntos musicais diversos. Os barcos "belamente iluminados", juntamente com os fogos queimados em grande quantidade, teriam produzido efeitos luminosos deslumbrantes.

O grande número de embarcações, todas ornamentadas e iluminadas, algumas nomeadas em referências aos eventos narrados nos Lusiadas, a presença da família imperial e da comunidade portuguesa, além da música e dos efeitos luminosos incomuns, tudo contribuía para criar o sentimento de exaltação patriótica e de presentificação das glórias lusitanas. Na regata, desvelava-se o heróico cenário da expansão marítima, onde em disputa náutica os "navegantes" intentavam conquistar o tão honrado prêmio, Os Lusiadas, "a alma de um povo".

Mas talvez o que mais surpreenda a nós leitores do século XXI, nas comemorações do tricentenário de Camões - realizadas num momento em que a historiografia destaca as críticas crescentes à monarquia e o avanço do movimento republicano - seja o fato dos jornais se referirem às festas populares.

O Jornal do Commercio destaca à comemoração da "mocidade academica" ao informar que alunos das escolas de medicina, politécnica e belas-artes

Reunidos em numero superior a quinhentos, quasi todos trazendo vistosas lanternas de variadas cores e formando as alas (...)com os seus estandartes alçados, percorrêrão (...) as principaes ruas do centro da cidade dando vivas ao immortal cantor dos Luziadas ${ }^{31}$.

Já a Gazeta de Notícias, do dia 12 de junho, descreve a movimentação das ruas:

Durante todo o dia de ante-hontem, eram as ruas atravessadas por grandes ondes de povo, que visitavam aquellas onde mais brilhantes eram os ornatos e festivos preparos. Entre essas, as do Ouvidor, Ourives, Quitanda, Candelaria, Luiz de Camões, apresentavam um lindo aspecto, todas embandeiradas e preparadas. A' noite além da illuminação a gaz em todas, tambem illuminaram-se muitas casas particulares, estabelecimentos publicos, etc. A rua do Ouvidor era principalmente concorrida, porque, alem da bella illuminação a gaz em toda a sua extensão, apresentava uma vista magnifica com os grandes festões de flores e globos de cores que pendiam dos arcos. Distribuiram-se pelas ruas versos impressos em diversas casas, no theatro D. Pedro II, na festa do theatro Gymnasio e do escriptorio d'esta folha distribuiram-se por vezes milhares de exemplares de poesias impressas avulsas em papeis de cores ${ }^{32}$.

Pelo que se pode ler nos jornais do mês de junho de 1880, as festas em

\footnotetext{
${ }^{31}$ Jornal do Commercio, 13/06/1880, n. 163, p. 01.

${ }^{32}$ Gazeta de Notícias, 11-12 de junho de 1880.
} 
comemoração a Camões ultrapassaram, em larga medida, os limites da colônia lusitana no Rio de Janeiro. Brasileiros e portugueses, populares e autoridades irmanaram-se no culto ao poeta, o que nos permite ao menos matizar a leitura tão consagrada pela historiografia brasileira sobre o período, que destaca a presença unívoca no espaço carioca de um forte antilusitanismo.

\section{Uma festa luso-brasileira}

É bem verdade que comunidade portuguesa, mas não apenas esta, marcou seu interesse pela comemoração do Tricentenário, organizando solenidades, prestando homenagens, distribuindo materiais gratuitos relacionados a Camões e sua obra, ou mesmo participando coletivamente em manifestações populares.

Tendo sido realizada, portanto, sob um modelo de festividade cívica próprio do final do século $X I X^{33}$, o Tricentenário da morte de Camões foi um terreno onde se pôde experimentar e fundamentar um imaginário correspondente aos projetos de transformação política e social tanto em Portugal como no Brasil.

Neste contexto, a obra de Camões, em especial Os Lusiadas, tornou-se ficção de fundação ${ }^{34}$, mito de origem, de Portugal e, por extensão, do Brasil. E nesta condição de mito, aquela que narra o momento primeiro que, num plano atemporal possibilita que a grandiosidade do passado português seja projetada em direção ao futuro como destino do povo - ou dos povos - lusitano.

Durante o período da festa, muitas vezes foi atribuída a Camões a condição de imortal ou eterno. Esta saída do tempo histórico teria, segundo os protagonistas das comemorações, se dado com sua própria morte “(...) em que, arrancado aos soffrimentos da vida terrestre, o poeta foi surgir no seio da immortalidade ao lado de seus iguaes ${ }^{, 35}$. Neste sentido, o Tricentenário evidenciaria a celebração não da morte, mas do "primeiro dia da vida immortal de Camões ${ }^{, 36}$. Assim, Camões eternizava-se pela ação e fala dos homens de 1880. Sua imortalidade era construída junto à patriótica comemoração de sua morte. A pátria fazia Camões imortal, e Os Lusiadas eternizavam suas glórias, cantadas "nos seus sublimes versos".

\footnotetext{
33 João, M. I. (2002). Op. cit, p. 48. p. 48.

${ }^{34}$ Aqui fazemos referência explícita ao livro de Summer, Dóris (2004). Ficções de fundação: os romances nacionais na América Latina, Belo Horizonte: UFMG.
}

35 Jornal do Commercio,11-12/06/1880, n. 162, p. 04.

${ }^{36}$ Jornal do Commercio,10/06/1880, edição especial, p. 01. 
Faz-se notável que durante o Tricentenário, a obra de Camões, em especial Os Lusíadas, tenha sido apreendida como o principal elemento construtor de sentido para a história lusitana e, por consequência, para a brasileira. O passado glorioso do povo português, tomado da obra de Camões, tornou-se a base de sustentação do ideal de civilização e progresso no qual se inseria não apenas as mudanças que se buscavam alcançar na política portuguesa, mas também o processo de construção da Nação brasileira.

A rejeição da época de decadência fez do Tricentenário um espaço intersticial onde se uniam as glórias passadas e o destino grandioso. E, tanto o passado como o futuro, elaborados neste momento, eram diretamente tributários dos versos do grande poeta. Nos acalorados discursos, poemas e artigos publicados e proferidos no Terceiro Centenário, a história de Portugal - e, por conseguinte, a do Brasil, - era frequentemente dividida em três etapas: o passado glorioso d'Os Lusiadas, o presente de renascimento ou rejuvenescimento e o grandioso futuro. Futuro no qual, em grande medida, se projetava o Brasil como herdeiro das glórias lusitanas. Nas comemorações do Tricentenário, ocultam-se as divergências entre Portugal e Brasil e evidencia-se a ideia de comunhão, de integração, cara àqueles que consideravam o universo cultural brasileiro necessariamente tributário das tradições lusitanas.

\section{Referências Bibliográficas}

Barbosa, Luisa Maria. O Brasil e o movimento republicano português, 1880-1910. (mimeo).

Caldeira, Ana Paula Sampaio (2009). A Biblioteca Nacional nos tempos de Ramiz Galvão (1870-1882), Rio de Janeiro: Biblioteca Nacional.

Catroga, Fernando (2005). Nação, mito e rito: religião civil e comemoracionismo, Fortaleza: Edições NUDOC/Museu do Ceará.

Ferreira, T. e Neves, Lucia. "As relações culturais ao longo do século XIX". In: Cervo, A. e Magalhães, J. C (2000). Depois das caravelas: as relações entre Portugal e Brasil, 18082000, Brasília: Editora da Universidade de Brasília.

João, Maria Isabel (2002). Memória e Império: comemorações em Portugal (1880-1960). Lisboa: Fundação Calouste Gulbenkian.

Ribeiro, Fernando Bessa (2005). "A invenção dos heróis: Nação, história e discursos de identidade em Moçambique". Etnográfica, vol. IX, n. 2. 
Sandmann, Marcelo (2003). "Marcelo Corrêa. As comemorações do tricentenário de Camões no Brasil”. Revista Letras, Curitiba, n. 59, jan./jun., Editora UFPR.

Serpa, Élio (2001). "Brasil e Portugal nas revistas portuguesas: língua, literatura e história". In: Ramos, Maria Bernadete, Serpa, Élio e Paulo, Heloísa (orgs.) (2001). O beijo através do Atlântico: o lugar do Brasil no panlusitanismo, Chapecó: Argos.

Serrano, Gisella Amorim (2009). Caravelas de papel. Tese (Doutorado) - UFMG, Belo Horizonte.

Summer, Dóris (2004). Ficções de fundação: os romances nacionais na América Latina, Belo Horizonte: UFMG.

Venâncio, Giselle Martins (2010). "Comemorar Camões e repensar a nação: o discurso de Joaquim Nabuco na festa do tricentenário de Camões no Rio de Janeiro". (mimeo).

Recebido para publicação em setembro de 2011.

Aprovado para publicação em dezembro de 2011. 